\section{The growth of nations}

\section{Michael Sargent enjoys a social history of how height and lifespan increased during the Industrial Revolution.}

$\mathrm{T}$ he idea that a wild mammal might reveal an unsuspected genetic potential for greater body size and for doubling its life expectancy in only 12-15 generations would astonish most naturalists. Yet this is exactly what happened to humans of the developed world after 1700 .

In a meticulous reconstruction of the recent evolution of human stature and longevity, The Changing Body convincingly links crucial episodes in social history with biological consequences using data extracted from obscure public records, such as military recruitment logs. The book's authors - a mix of economists and social historians - ascribe these trends in the development of the human body to a synergy between technological advance and physiological adaptation, which led to improved health, agricultural yields and industrial productivity.

This virtuous circle of progress produced extraordinary improvements in lifespan. The increase in longevity - one of the most important outcomes of the Industrial Revolution - originated largely in the greater robustness and capacity of vital organ systems, changes that are endorsed by recent insight into human development.

The book explains how advances in health and longevity were aided by a mysterious increase in fertility that began in "Since 1950, the height of US-born males has declined, whereas Dutch males have emerged as the world's tallest."

the seventeenth cen-

tury. This, coupled with the improved food production and distribution of the agricultural revolution, powered a population explosion without provoking a subsistence crisis. Improved sanitation and publichealth management in the late nineteenth century helped to prevent the spread of infectious disease, further boosting productivity by massively reducing the time workers lost to sickness.

The authors surmise that most eighteenthcentury Europeans barely consumed enough calories to meet the minimal maintenance requirements of the human body, based on estimates of food available and contemporary descriptions of diet. One-fifth of the population subsisted on even less: beggars and paupers, too weak to work effectively. From 1800, the authors argue, a higher calorie intake and reduced risk from infectious disease led to increased industrial efficiency. Slave masters in the old American plantations understood this issue well, providing substantial rations of cornmeal, salted herrings and pork to get more work out of their labour force. By contrast, many Europeans were stunted, except for the better-fed social elite. For example, between 1750 and 1860, officer cadets at Sandhurst, the British army's training college, were 14 centimetres taller on average than recruits to the British merchant navy, who came from the poorest strata of society.

The authors make use of charts showing the relationship between height, weight and risk of death in modern Norwegians and in veterans of the American Civil War, which they extrapolate to Europeans from 1700 onwards. Improved nutrition, they say, was the biggest factor in reducing death risk until the 1870 s, and declining exposure to infection became more significant thereafter.

Average stature, as a quantitative measure of human welfare, gives insight into circumstances affecting an entire population. For example, following US independence in 1766, early male settlers became the world's tallest men, with longer lifespans than their European peers (57 years compared with 40 years in Europe) thanks to a greater abundance of food. But by the mid-nineteenth century, US food producers were struggling to feed the rapidly rising population, and the average height of US males fell by $4.4 \mathrm{~cm}$.

Childhood diarrhoeal infections also caused stunting of this generation: epidemics were rife in the densely populated cities of the
ЭNATURE.COM For more on how nutrition affects fetal development: go.nature.com/kwxtkb eastern seaboard, which teemed with immigrants. Forty years later, the drop in calorie intake that affected many during the Great Depression of the 1930s had little effect on stature because by then, the country had in place a fully developed system for controlling the spread of infectious disease.

Since 1950, the height of US-born males has declined slightly, whereas Dutch males have emerged as the world's tallest, by $4.5 \mathrm{~cm}$ on average. This could indicate greater equality of nutritional opportunity in childhood in the Netherlands compared with the United States. However, the emergence of a genetic difference previously obscured by undernutrition is also possible - a hypothesis that could be tested on people of Dutch descent living in the United States. Another possibility not considered by the authors is that shorter migrant families could be contributing to the statistics.

The complex and original narrative in The Changing Body is the culmination of decades of detective work, embracing the diverse histories of many nations. The statistical analysis involved is subtle, sophisticated and must be taken on trust by most of us. The conclusions, however, are convincing and reveal aspects of our biological history that could not have emerged in any other way. They are also consistent with current understanding of the determinants of stature and longevity; prenatal malnutrition undermines full development of the vital organs of the adult body, making premature age-related diseases more likely.

Using data showing that US Civil War veterans succumbed to age-related diseases well in advance of comparable groups in modern society, the authors provide striking support for the idea that the longevity of this age group within a population is affected by similar experiences in early life. Developmental biologists are accumulating evidence showing that the function of crucial genes is modified in utero by an epigenetic process that does not alter the DNA sequence - which reduces organ development and has consequences for robustness in later life. These changes can be transmitted to the next generation, explaining the need for several generations to elapse after a nutritional improvement before a smallstature trait is lost.

The anthropometric approach to history described in this book is impressive and skilful, and is likely to become routine in the study of future influences on human development.

Michael Sargent is at the National Institute for Medical Research, Mill Hill, London and author of Biomedicine and the Human Condition.

e-mail:msargen@nimr.mrc.ac.uk 